\title{
The Impact of Students' Industrial Training on their Employability Status after Graduation: Evidence from Kumasi in Ghana
}

\author{
Ayogyam Alexander*, Appienti Ansah William, Jenkins A. Asaah, Abubakari Zakari
}

Kumasi Polytechnic, Ghana

*Correspondence E-mail:ayogyama@yahoo.com

\begin{abstract}
A current development in Ghana where students graduating from the tertiary institutions find it difficult to secure employment has become extremely worrisome. Employers have complained over the years that, though students are knowledgeable, they lack practical skills hence they become less useful to industry. Realizing this deficiency, many institutions have developed industrial training model to address the issue. The study therefore sought to investigate the effect industrial training could have on students' employability. A cross sectional research was conducted on employers in the Kumasi Metropolis in the country. Three groups of respondents were sampled namely; employers, jobless graduates seeking employment and graduates already employed. In respect of these groups, 93 employers and 120 graduates were sampled for the research. Since the sampled size was greater than 30, the Wilcoxon sign rank test was adopted to test for significant difference between two scenarios in each variable so that the research hypothesis be decided on. The wilcoxon's signed ranked test concluded that alternate hypothesis $\mathrm{H}_{1}, \mathrm{H}_{4}$ and $\mathrm{H}_{5}$ were accepted whiles their respective null hypothesis be rejected. Contrary, alternate hypothesis 2 and 3 were rejected whiles their null hypothesis accepted because the scenarios used for the test in the respective variables indicated no significant difference.
\end{abstract}

Keywords: Employability, Graduation, Industrial, Status and Kumasi, Ghana Training.

\section{Introduction}

The practice of subjecting students to more theoretical background of real life situations as against the practical orientation has become highly unacceptable in the Ghanaian society today. Many students with the theoretical orientation end up unemployed and the number keeps increasing exponentially. Based on the preliminary field discussions, it was gathered that, the unemployment situation in the country can be attributed to the changing focus of employers. The depreciation of the Ghanaian currency and other macro economic factors which are beyond the control of the employer is been given less attention when dealing with cost reduction. Rather, employers are now focusing on micro economic factors' within their control to manage their operational costs. Every business owner prefers to engage the services of versatile people so that they can benefits from their theoretical knowledge as well as practical experiences. This brings to mind the characteristics of a versatile graduate in Ghana. Obviously, graduates become highly employable if they are doctored with a mixture of theory and practical. Many tertiary institutions in the country have adopted industrial training as a module so that students could have practical exposure whiles in school. In line with employers' expectations, students would have the feel of real life situations before they graduate. According to Stuliff [1] industrial exposure gives the academics a chance to seek inputs and feed back from practicing professionals who can provide valuable insight into the skills and abilities students would need in their career. It is also an opportunity for students to personally practice the theoretical models in the classroom to enhance their chances of securing employment after graduation [2]. In addition to this advantage, students are re-shaped perceptually and psychologically to be on top of any practical encounter. This psychological disposition serves as a bridge between the world of theoretical learning and practical exposure [3, 4].

In Ghana, Industrial training for students has not achieved the expected results due to some challenges. It was discovered that inappropriate placement of students and poor supervision during training [5], reluctance to allow students to use industrial facilities for training [6] have contributed to the ineffectiveness of industrial training. Since employers are looking beyond the 
graduate's academic knowledge, students who are hit by these short comings become non competitive.

It is however believed that, when industrial training produces favorable effect on graduate's employability, stakeholders would assist in the eradication of the challenges indicated above. Another motivation for this research work was derived from the fact that some developed nations have realized the need to augment the traditional education programs. Since the traditional programs were not adequately addressing the needs of industry, Wright [7] recommended skills acquisition in higher education in the United Kingdom through Enterprise in Higher Education (EHE).

\section{Review of Literature and Hypothesis Development}

Though Ramli et al. [8] are convinced that, there were some challenges in their bid to connect 28 schools in Malaysia to the work environment, other researchers made recommendations towards making the young graduate highly competitive in the job market through practical skills. The phenomena below are very crucial in making graduates employable.

\section{Graduate Skills and the Job Market}

The dictates of the job market redirected the focus of future leaders. Future leaders are therefore expected to embrace all facets of skills acquisition. According to Liyanage and Poon [9], education needs overhauling not only in content and delivery modes but also in a way it is used to promote the knowledge management process in organizations. It has been reiterated that a deficit in graduate skills emanating from mismatch between the skills a graduate acquires and the expectations of employers; less recognition for academic competence would hardly guarantee a job placement [10, 11]. Since employers have varying values for different skills, Cox and King [12] are of the view that graduates must acquire all the requisite skills so that they could meet the expectations of many employers. From the body of knowledge from the literature, the hypothesis $\mathrm{H}_{1}$ is then tested.

$H_{1}$ : Acquisition of varying skills by the graduate through industrial training increases the likelihood of securing employment.

\section{Industrial Training and Competencies}

Competency is the ability to apply or utilize knowledge, skills and some attributes acquired through training to perfectly perform some functions or work task [13-15]. It is now known Ayogyam Alexander et. al. | July.-Aug. 2012 | Vol.1 | Issue 4|108- 114 that, the level of competency to be displayed by someone can be aided by the motivation derived from the work itself and the perception of one's self [16-18]. Though competency can be acquired through training and experience, some are naturally competent which is considered intrinsic. People with this intrinsic characteristic do not need intensive coaching to produce a good work [19].The hypothesis below is then proposed for testing.

\section{$\mathrm{H}_{2}$ : The level of competency acquired through training can enhance employability. \\ Experiential Learning and Trainig Approaches}

Learning from experience is very fundamental and so it tends to redefine personalities. Learning results in a permanent change of knowledge and attitude which can be achieved through formal structures or informal dimension such as experiences [20]. A similar argument by Kolb [21] describes learning as a transformation of one's experience. It is therefore obvious that when someone's experience is being transformed, a value addition occurs. According to Coll et al. [22] a model proposed by Lewin towards experiential learning involves experience, observation and reflection, formation of concepts and the testing of these concepts in an entirely new situation. A similar model by Dewery also cited by Coll et.al. [22] claims that the impulse of experience is a means of providing ideas with a moving force that provides action. Huntington [23] recounts how industrial training was moved from collaborative status at the Manchester Metropolitan University to become a scoring model in the retail marketing program under the request of students in 1995. Students were then assessed on training experience, hence alerting them to be more committed than ever before. The new approach made the commitment level of students very high. The School of Technology and Design at University College of Northampton made an arrangement with local entrepreneurs to assist in enhancing students' practical knowledge. Students therefore had the opportunity to gain both academic and practical work in appropriate fields. The arrangement allowed the school to selectively engage companies that could offer training in the field of study of the students concerned [24]. The approach adopted could ensure that lecturers and students interact with practicing professionals for mutual benefit. Stuliff [1] therefore proposes collaboration between the industry and schools so that lecturers can improve their mode of delivery while students enrich their practical knowledge. 
$H_{3}$ : Exposing students to alternative ways/approaches of acquiring training increases the likelihood of getting employed after school.

\section{Standadised Criteria Awareness}

When students are made aware of the standardized criteria for employment, they would direct their training focus at areas that would meet employers' requirements. Steward and Knowless [25] support this view in their research which identified that communication skills, leadership skills, organizational ability and teamwork are some of the skills required by employers. The skills were also identified as being influential in successfully performing in a position one finds himself/herself [14,17,18]. The study therefore tested the hypothesis below in order to conclude on the proposition.

$H_{4}$ : Being aware of the skills required by employers increases the likelihood of getting employed.

\section{Business Ownership Experience}

Exposure to business at a tender age can propel people into entrepreneurship. By so doing, they eventually become employers. The institute of Entrepreneurship and Enterprise Development at Kumasi Polytechnic in Ghana developed a model in 2006 to encourage students to set up businesses. Many of these students have graduated into their businesses and so they are gainfully employed and even employ others. The few who are not able to graduate into their business for some reasons become the favorites for other employers because they seem to have the appropriate qualities and skills.

$H_{5}$ : Developing the spirit/culture of business ownership as a result of operating a business at school is likely to influence employers and increase the confidence to be self employed.

\section{Methodology of the Research}

The study sought to explain the extent to which some phenomena vary with respect to employability. It actually examined some scenarios in the selected phenomena discussed above and the outcomes were related to the ability to secure employment after graduating from school. The relationship existing between variables in some particular cause and effect were also examined and explained rendering the research an explanatory one [26].

Two groups of respondents were used for this study. The first was a group of employers within Kumasi Metropolis in Ghana and the second was a group of tertiary students who had graduated from either the university or the polytechnic. For graduates, the research considered those who were then seeking for jobs and those who were gainfully employed. Employers were made to respond to questions bordering on graduates suitability for vacancies they had and the reasons that informed their recommendation for selecting graduates they currently work with. Graduates were also made to address issues on the difficulty they encountered during their search for jobs.

Multiple sampling methods were adopted for the research. The numerous graduates and employers were groups using stratified sampling procedure. Three different strata were formed representing graduates from school who were seeking for jobs; graduates who were already employed (either self or wage employment); and employers who were seeking the services of graduates. From each Stratum, respondents were selected using simple random sampling technique. The sample size used for the research was carefully chosen to produce greatest diversity of the variables used [27]. In conformity with Moser and Kalton and Henry $[28,29$ [ the study resolved to use a sample for the research to ensure overall accuracy instead of a census and also to stay within budget. In line with this a sample size of 120 was picked for students and 93 for employers.

The study used some data that has already been collected for some other purpose [30]. Whenever it become obvious that it was difficult to test current hypothesis using existing data because it could not be relevant to the current study, primary data was collected using the sample [31]. Since the study intended not to influence the thoughts of respondents, questionnaires were used as the data collection tool as recommended by [32].

The data was qualitative in nature so the Wilcoxon's signed ranked test which is nonparametric test was appropriate in this research. For each variable in the study, two distinct scenarios were described. In each case, it was assessed whether or not the groups or scenarios were significantly different using paired z-test. The z-test was applicable because, the sample size used in the study was greater than 30 and so it was near normal. This compared the difference in the means of the two groups using a measure of the spread of the scores. If the two variables are significantly different this will be presented by a $\mathrm{p}$-value whose probability is less than 0.05 $(\alpha=0.05$ or $5 \%)$. Empirically, to calculate the significant of the test statistic (T) we consider; 
Table1: Table showing significant difference between ASBC and NASBC wilcoxon signed ranks test

\begin{tabular}{lllll} 
& & N & Mean rank & Sum of ranks \\
\hline NASBC - ASBC & Negative Ranks & $8^{\mathrm{a}}$ & 17.00 & 136.00 \\
& Positive Ranks & $25^{\mathrm{b}}$ & 17.00 & 425.00 \\
& Ties & $26^{\mathrm{c}}$ & & \\
& Total & 59 & & \\
\hline
\end{tabular}

$a$ is for NASBC $<$ ASBC

$\mathrm{b}$ is for NASBC $>\mathrm{ASBC}$

c is for NASBC $=$ ASBC

\section{Test statistics ${ }^{b}$}

\begin{tabular}{ll}
\hline & NASBC - ASBC \\
\hline$Z$ & $-2.959^{\mathrm{a}}$ \\
Asymp. Sig. (2-tailed) & .003 \\
\hline
\end{tabular}

a. Based on negative ranks.

b. Wilcoxon signed ranks test

Table 2: Table showing significant difference between SWDC and SWNDC wilcoxon signed ranks test

\begin{tabular}{|c|c|c|c|c|}
\hline & & $\mathbf{N}$ & $\begin{array}{l}\text { Mean } \\
\text { rank }\end{array}$ & Sum of ranks \\
\hline \multirow[t]{4}{*}{$\begin{array}{l}\text { SWNDC } \\
\text { SWDC }\end{array}$} & $\begin{array}{l}\text { Negative } \\
\text { Ranks }\end{array}$ & $21^{\mathrm{a}}$ & 24.00 & 504.00 \\
\hline & $\begin{array}{l}\text { Positive } \\
\text { Ranks }\end{array}$ & $26^{\mathrm{b}}$ & 24.00 & 624.00 \\
\hline & Ties & $49^{c}$ & & \\
\hline & Total & 96 & & \\
\hline
\end{tabular}
a. SWNDC $<$ SWDC
b. SWNDC $>$ SWDC
c. $\mathrm{SWNDC}=\mathrm{SWDC}$

Test statistics ${ }^{b}$

SWNDC - SWDC

$\mathrm{Z} \quad-.729^{\mathrm{a}}$

Asymp. Sig. (2tailed)

a. Based on negative ranks

Table 3: Table showing significance difference between MATT and FATT

\begin{tabular}{lllll} 
& & N & \multicolumn{2}{c}{ Mean rank Sum of ranks } \\
\hline FATT & - Negative & $18^{\mathrm{a}}$ & 17.50 & 315.00 \\
MATT & Ranks & & & \\
& Positive Ranks & $16^{\mathrm{b}}$ & 17.50 & 280.00 \\
& Ties & $62^{\mathrm{c}}$ & & \\
& Total & 96 & & \\
\hline
\end{tabular}
a. FATT $<$ MATT
b. FATT $>$ MATT
c. $\mathrm{FATT}=\mathrm{MATT}$

Test Statistics ${ }^{\mathrm{b}}$

\begin{tabular}{ll}
\hline & FATT - MATT \\
\hline $\mathrm{Z}$ & $-.343^{\mathrm{a}}$
\end{tabular}

Asymp. Sig. $\quad(2-$ tailed) 
Table 4: Table showing significance difference between BAEM and NBAEM wilcoxon signed ranks test

\begin{tabular}{lllll}
\hline & & N & Mean rank & Sum of ranks \\
\hline NBAEM - BAEM & Negative Ranks & $0^{\mathrm{a}}$ & .00 & .00 \\
& Positive Ranks & $18^{\mathrm{b}}$ & 9.50 & 171.00 \\
& Ties & $9^{\mathrm{c}}$ & & \\
& Total & 27 & & \\
\hline
\end{tabular}
a. NBAEM < BAEM
b. NBAEM > BAEM
c. NBAEM $=$ BAEM

Test statistics ${ }^{b}$

NBAEM - BAEM

$\mathrm{Z} \quad-4.243^{\mathrm{a}}$

Asymp. Sig. (2-tailed)

.000

a. Based on negative ranks.
b. Wilcoxon signed ranks test

Table 5: Significant difference between HSOW and HNSOW Wilcoxon signed ranks test

\begin{tabular}{lllll}
\hline & & N & Mean rank & Sum of ranks \\
\hline HNSOW - HSOW & Negative Ranks & $45^{\mathrm{a}}$ & 27.00 & 1215.00 \\
& Positive Ranks & $8^{\mathrm{b}}$ & 27.00 & 216.00 \\
& Ties & $47^{\mathrm{c}}$ & & \\
& Total & 100 & &
\end{tabular}
a. HNSOW $<$ HSOW
b. HNSOW $>$ HSOW
c. HNSOW $=$ HSOW

Test statistics ${ }^{b}$

\section{HNSOW - HSOW}

Z

Asymp. Sig. (2-tailed)

a. Based on positive ranks.
b. Wilcoxon Signed ranks test

The empirical model

$\mathrm{T}=\frac{\mathrm{n}(\mathrm{n}+1)}{4} \sqrt{ }$

$\mathrm{SE}_{\mathrm{T}}=\mathrm{n} \underline{(\mathrm{n}+1)(2 \mathrm{n}+1)}$

24

$\mathrm{T}=$ the test statistic, $\mathrm{SE}_{\mathrm{T}}=$ Standard error and $\mathrm{n}$

$=$ the sample size

For a large sample size greater than 30 , the $\mathrm{z}^{-}$ score or $z^{-}$-statistic is applied, Since T, T and $\mathrm{SE}_{\mathrm{T}}$ are known then $\mathrm{z}$ can be calculated as;

$$
\mathrm{Z}=\frac{\mathrm{X}-\mathrm{X}}{\mathrm{S}} \quad \text { or } \quad \mathrm{z}=\frac{\mathrm{T}-\mathrm{T}}{\mathrm{SE}_{\mathrm{T}}}
$$

$-5.082^{\mathrm{a}}$

.000

Using the Wilcoxon signed test software and the coded data, the table of values are then obtained. For each of the variables, two scenarios were used for the test.

\section{Scenarios in the Hypothesis}

In hypothesis 1 , the independent variable was 'acquisition of varying skills' and the dependent was 'employability'. The independent variable was represented by 'Acquiring skills before completion' (ASBC) and 'Not acquiring skills before completion' (NASBC). These were the two scenarios tested for significance.

In hypothesis 2 the independent variable was 'Students with degree of competency' and so the two scenarios were 'Students with degree of 
competency' (SWDC) and 'Students with no degree of competency' (SWNDC).

In hypothesis 3 , the independent variable was 'the number of approaches to training'. The two scenarios were 'having many approaches to training' (MATT) and 'few approaches to training' (FATT).

In hypothesis 4 , the independent variable was 'being aware of employers measure'. The two scenarios are therefore 'Being aware of employers measure' (BAEM) and 'Not being aware of employers measure' (NBAEM).

In hypothesis 5 , the independent variable was 'students having spirit of ownership towards work'. The two scenarios were 'having spirit of ownership' (HSOW) and 'having no spirit of ownership' (HNSOW).

\section{Result and Discussion}

From table 1, the asymptotic significance also known as the $\mathrm{p}$-value or the probability was 0.03 which was less that $\mathrm{\alpha}=0.05$ or $5 \%$ level. This means that, the variable (students acquiring skills before completing school) is significant at $5 \%$. It therefore means that, the two scenarios (ASBC and NASBC) significantly different. As a result of this, for a student to be employed after school, it matters so much about whether he/she had some kind of skills before graduating. Hence employers actually made a choice as to which group of graduates to employ and those not to employ based on the two scenarios. Table 2 indicates a probability value of 0.466 which is greater than $a=0.05$. This showed that, the variable (students with some degree of competence) had insignificant effect on the dependent variable. Hence the two scenarios for this variable (SWDC and SWNDC) had no significant difference between them. It followed therefore that, a student being competent at the job before graduating would not inform the choice of the employer. In the third table, the variable (having different approaches to training) showed a probability value of 0.732 which was far greater than $\alpha=0.05$ and so it implied that the variable was insignificant and so there was no significant difference between the two scenarios. Whether a

\section{References}

1. Stuliff K (2000) Integrating academics and industry: A challenge for both sides. In ACM J. Computer Documentation 24(1):33-8.

2. Ballinger RC, Lalwani CS (2000) The role of internships in marine policy and integrated coastal student had few or many approaches to training, it did not affect the chances of securing employment after graduation. Employers did not consider the MATT and FATT scenarios as conditions for employment. The result tables 4 and 5 indicated a highly significant effect for the variables (being aware of employers' measure and having the spirit of ownership) on the dependent variable. The scenarios corresponding to each variable had significant difference between them. This high level of significance was as a result of a probability value of 0.000 which was less than $\alpha=0.05$. These variables were actually significant at $1 \%$ level. Consequently, the two pair of scenarios BAEM/NBAEM and HSOW/HNSOW showed strong significant differences. Therefore two students with different degrees of knowledge about employer's measures for employment would have different chances of securing jobs. Also, if a student once owned a business or had spirit/culture of ownership, the chance of securing a job will not be the same as someone without spirit/culture of ownership [33-35].

\section{Conclusions}

It is hereby concluded that, students' industrial training cannot be taken for granted because it does has a great effect on their employability after graduation. According to the study, students need the practical skills to secure jobs, however competency can be acquired on the job. Though skills acquisition is important, not every skill acquired adds value to the student. This is a revelation from the results in table 1 . Therefore, the variety of skills acquired does not really matter but rather the ability to identify the most relevant per employers' expectations.

\section{Recommendation}

Based on the research, it is recommended that students must endeavor to acquire skills before they graduate from the tertiary institutions in other to enhance their employability. They should march their skills acquisition with the expectations of employers so that, they can end up with relevant skills. Authorities in the tertiary institutions should ensure that relevant industrial training is incorporated into the curricula of all departments.

management higher education. Ocean and Coastal Management 43:409-29.

3. Teichler U (1998) The requirements of the world of work. In Proceedings of the world conference on higher education-higher education in the twenty- 
first century. Vision and Action Volume IV. UNESCO.

4. Teoh S (2006) Industry explores internship issues. In The Star Online.

5. Afonja AA, Sraku-Lartey K, Oni SA (2005) Engineering education for industrial development: Case studies of Nigeria, Ghana and Zimbabwe. ATPS Working Paper No. 42. Nairobi, Kenya: The African Technology Policy.

6. Kofoworola OF (2003) Engineering education in Nigeria: Present learning systems and challenges for the future. Australasian J. Engineering Education.

http/www.aaee.com.au/journal/2003/koforworola03. pdf 3-5.

7. Wright $\mathrm{P}$ (1992) Learning through enterprise: the EHE initiative' in Higher Education Quality Council (HEQC). Learning to Effect (London, HEQC).

8. Ramli M, Mohd Sani I, Abu A (2001) Tech-prep and school-to-work reforms in Malaysia: Meeting the global challenges. In IVETA Annual conference 2001, Montego Bay, Jamaica.

9. Liyanage S, Poon PS (2003) Technology and innovation management learning in the knowledge economy: A techno-managerial approach. J. Management Development 22(7):579-602.

10.Morgan A, Turner D (2000) Adding value to the work placement: working towards a professional qualification in an undergraduate degree programme. Education + Training 42(80):453-61.

11.Fallows S, Steven C (2000) Building employability skills into the higher education curriculum: a university-wide initiative. Education + Training $42(2): 75-83$.

12.Cox S, King D (2006) Skill sets: an approach to embed employability in course design. Education + Training 48 (4):262-74.

13.Dubois DD (1993) Competency-based performance improvement: a strategy for organizational change Amherst, MA: HRD Press, Inc.

14.Boyatzis RE (1982) The competent manager: a model for effective performance New York: Wiley.

15.Fogg CD (1999) Implementing your strategic plan: how to turn "intent" into effective action for sustainable change New York. American Management Association.

16.Fulmer RM, Conger JA (2004) Identifying talent. Executive Excellence 21(4):11.

17.Gangani N, McLean GN, Braden, RA (2006) A competency-based human resources development strategy. Performance Improvement Quarterly 19(1):127-39.
18.Sandberg J (2000) Understanding human competence at work: An interpretative approach. The Academy of Management Journal 43(1):9-25.

19.Spencer LM, Spencer (1993) Competence at work. New York: Wiley.

20.Walton J (2005) Would the real corporate university please stand up? J. European Industrial Training 29(1):7-20.

21.Kolb DA (1984) Experiential learning: Experience as the source of learning and development. Prentice-Hall, Englewood Cliffs. NJ.

22.Coll RK, Lay MC, Zegwaard KE (2002) Enhancing access to experiential learning in a science and technology program. J. Vocational Education and Training 54(2):197-217.

23.Huntington S, Stephen J, Brenda M Oldfield (1999) Formal assessment of student placement within a retail sandwich degree. Industrial and commercial training 31(3):106-11.

24.Stringer DJ (1999) Three year honours Deegree with an integrated one year industrial placement, vocational technology-engineering for the future? In IEE seminar, pp.7/1-7/4.

25. Stewart J, Knowles V (1999) The changing nature of graduate careers. Career Development International 4(7):370-83.

26.Gill J, Johnson P (1991) Research methods for managers. Paul Chapman, London.

27.De Vaus DA (1991) Surveys in social research(3 $3^{\text {rd }}$ edn). UCL Press and Allen\& Unwin.

28.Moser CA, Kalton G (1986) Survey methods in social investigation $\left(2^{\text {nd }} e d n\right)$. Aldershot, Gower.

29.Henry GT (1990) Practical sampling. Newbury Park,California.

30.Hakim,C.(1982).Secondary analysis in social research. Allen\& Unwin,London.

31.Stewatt DW, Kamins MA (1993) Secondary Research: Information sources and methods, $2^{\text {nd }}$ ed. Newbury Park California Sage.

32.Kervin JB (1992) Methods for business research. HarperCollins, New York.

33. Field A (2005) Discovering statistics and using SPSS. SAGE Publications, pp570

34.Lucia AD, Lepsinger, $R$ (1999) The art and science of competency models: Pinpointing critical success factors in organizations. New York: Pfeiffer.

35.Saunders M, Lewis P, Thornhill A (2003) Research Methods for Business Students (Third Edition), London: Financial Times-Prentice Hall. 